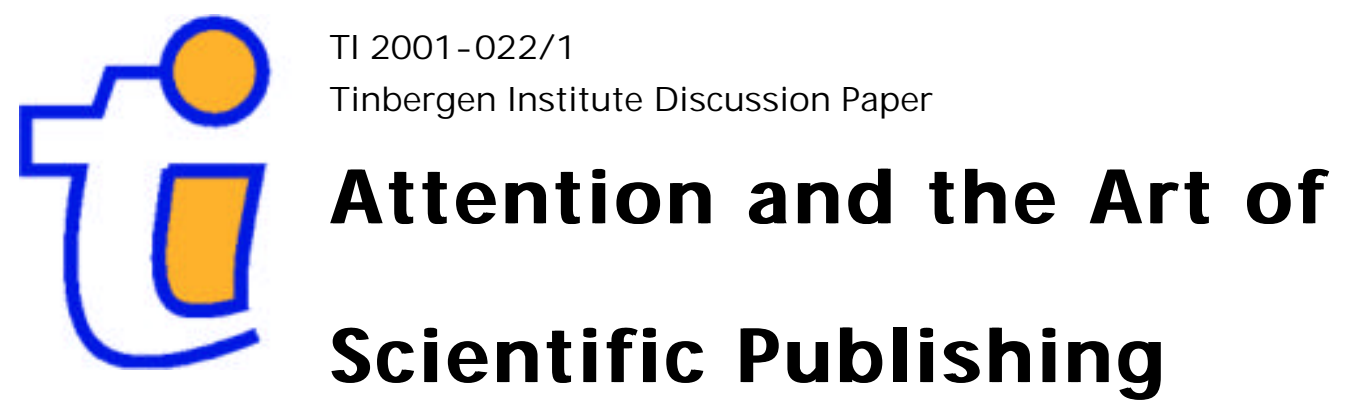

Arjo Klamer

Hendrik P. van Dalen 


\section{Tinbergen Institute}

The Tinbergen Institute is the institute for economic research of the Erasmus Universiteit Rotterdam, Universiteit van Amsterdam and Vrije Universiteit Amsterdam.

\section{Tinbergen Institute Amsterdam}

Keizersgracht 482

1017 EG Amsterdam

The Netherlands

Tel.: $\quad+31 .(0) 20.5513500$

Fax: $\quad+31 .(0) 20.5513555$

\section{Tinbergen Institute Rotterdam}

Burg. Oudlaan 50

3062 PA Rotterdam

The Netherlands

Tel.: $\quad+31 .(0) 10.4088900$

Fax: $\quad+31 .(0) 10.4089031$

Most recent TI discussion papers can be downloaded at http:// www.tinbergen.nl 


\title{
Attention and the Art of Scientific Publishing
}

Arjo Klamer* and Hendrik P. van Dalen**1

February 12, 2001

* Erasmus University Rotterdam

Faculty of History and Arts

P.O. Box 1738

NL-3000 DR Rotterdam

The Netherlands

Email: klamer@fhk.eur.nl

Tel: +3110 - 4088621

** Erasmus University Rotterdam

Research Center for Economic Policy and Tinbergen Institute

P.O. Box 1738

NL-3000 DR Rotterdam

The Netherlands

Scientific Council for Government Policy

P.O. Box 20004

NL-2500 EA The Hague

The Netherlands

Email: dalen@wrr.nl

Tel: $+3170-3564668$

Fax: $+3170-3562695$

\begin{abstract}
:
Attention is the coordination device which makes modern science work the way it does. A typical characteristic of attention in the scientific world is that those who seek attention are the same people who are giving it. Another important feature within groups is the skewed distribution of attention. We discuss the effect these characteristics have on scientific institutions. An important thesis is that scientists converge in clusters of likeminded scientists. Given the character of scientific organisation and communication we expect that the digitalisation of scientific communication will not affect the basic scientific institutions as the principles upon which the Internet and open source code projects function coincide more or less with the way science functions. The channelling of attention will remain an important issue as the flood of information in the age of electronic publishing will only increase.
\end{abstract}

\footnotetext{
${ }^{1}$ We thank Olav Velthuis for calling attention to the factor of attention, and participants in a conference on scientific publication, the philosophy of economic economics and the seminar in cultural economics, all at the Erasmus University, for their criticisms.
} 
"Many of you will conjure up reasons why the number of citations should be ignored. There are fads; there are self-citations; there are conspiracies; there are derogatory citations; there are bribes to editors and referees; there are sycophantic students; and there are subjects capable of direct understanding by only a few. But why didn't your paper start fads; why don't you publish more and cite yourself; why did your conspiracies fail; why don't you become an editor; why don't your students care about your welfare; and why don't you insist on writing about obscure issues?" - Ed Leamer (1981)

\section{Introduction}

Some will welcome a digital future for scientific communication as a liberation. After all, everyone will be free to publish their findings on the internet to be read by anyone. Gone will be the tough and ruthless competition for the scarce slots in the limited number of journals that count, gone will be the narrow-minded and self-congratulatory referees and editors who stand in the way of publication, gone will be the long lags in publication, and gone will be the high fees of journals, the trips to the library, and the endless copying. The communication of one's research will be immediate and free, and so will be the reading of that research. Liberation therefore. Think again. Consider the characteristics of the process of scientific communication and you should expect that some institutional changes notwithstanding getting one's ideas recognised will be as tough and arduous a process as ever, if not more.

The key is attention. Even though digital technology may make it easier to get one's ideas out into the public realm, say on a personal web-site, this does not mean that they will be read, cited and discussed. Easier access also means more excess. The sheer abundance of texts to be read will render the chance of being noticed at all minimal. The web may expand the space in which we can communicate with each other, but the expanse of that space will confront us with the problem of attention more than ever before. Attention, so we will argue here, is a better interpretive device for understanding the various practices in the modern world of science than modelling scientists as truth seeking individuals or by assuming that scientists are driven by monetary incentives.

This paper focuses on the role of attention in the world of science in general and in the world of economics in particular. It shows how problematic attention really is, and how scientists/economists have coped with the problem thus far. The objective is to anticipate the institutions that will help scientists cope with excess on the web.

Since the literature in economics and economic methodology has so far not explicitly identified the problem of attention in economics, we have to develop a theoretical perspective on the role of attention in the production and dissemination of scientific knowledge. (As this is a journal of economic methodology and we are economists, the argument relates most to economics but applies to other sciences as well.) We first present a few stylised facts of scientific communication.

\section{The Harsh Facts of Scientific Publishing}

Scientists have an inner drive to reveal their findings as quickly as possible to their peers and the conventional way to make knowledge accessible is to publish research in journals. Of course, scientists are only human and they want to attention and get credit for their work. In short scientists do research (a) to get published and (b) to get cited. Especially now the budgeting for scholarly research appears to be getting tighter, the "publish or perish" principle is as true as ever. Promotions, 
hiring and firing in academia, they are to a large degree related to the attention record of scholars (Hargens and Schuman, 1990; Siow, 1998).Yet, not any publication will do. In order to get cited it is important to get published in the right (analog) journal. Being in the right journal is a necessary but not a sufficient condition for getting the right attention. Being noted is a necessary condition for being persuasive, gaining a reputation, receiving tenure, getting funded and so on. Noting the work of colleagues is a necessary part of partaking in the game of science.

Anyone who partakes in this process of seeking attention and paying attentions to others who are seeking it, faces the two harsh facts of scientific publication. The first fact is the inflation in number of publications that call for our attention. The second harsh fact is the skewed distribution of attention over all those publications.

The first harsh fact of scientific publishing confronts all people who participate or aspire to participate in scientific discourse and concerns the inflation of the number of publications. If Ulrich's Complete International Database is of any guidance in this the journal publication numbers must be considered impressive. In 1999 there were 165,000 serials registered by 80,000 publishers world wide covering 969 subjects ranging from anthropology to zoology. In that year 10,000 serials ceased to exist whereas 6,000 serials were born and added to the stock of journals. Of course, not every serial is as important and scholarly as we imagine these scientific journals to be. A lot of these journals stick to reporting facts that border on scientific journalism. The more scholarly journals rely on refereeing and this number is considerably smaller as 12,600 journals are registered as 'refereed journals'. And to put this number even more in perspective, the authoritative Institute for Scientific Information which reports on a quarterly basis the citations registered in set of scholarly journals considers 'only' 7,000 refereed journals as constituting the core of the scientific conversation. But not only do scientists have to cope with competition for attention in publishing their material it is also a competition that has become fiercer and fiercer with the growing of time. The estimated growth of journals published in the US increased with 62 percent between 1975 and 1995 (from 4,175 journals in 1975 to 6,771 in 1995). There is a steady growth in number of publications and hence the growing number of articles published. More and more articles ask to be read; no single scholar can possibly cover them all even though scientists are reading slightly more articles than 25 years ago (Tenopir and King, 1998).

At the same time the ranks of scientists have swollen. The activity of citing each other has increased. Figure 1 shows how over time the number of references used in articles registered by the SSCI has risen steadily from 7 references per article to 22 references. At the same time the average number of citations received per cited author (and let us assure you that the large majority of scholars does not get cited for the work they have done) has increased from 3.4 to 5.0 citations per year. In other words, the value of a citation in 1996 is 68 per cent of the value of a citation in 1969.

Of course, the growing number of publications has been facilitated by the increasing number of journals which in turn has been inspired by the increasing number of researchers or, to be more precise, the increasing number of specialised researchers. Specialisation has become a necessity today. If the Renaissance man would be able to cover a literature across the intellectual spectrum, that achievement would be virtually inhuman today. There is simply too much out there for any single individual to take notice and read. And each and every reader has to allocate his scarce reading time to the articles which appear ex ante as the best among a pool of competing articles. And even then he will have to put an effort in to keep abreast of his research field. Holub et al. (1991: 324) calculate that experts who read about 30 articles a year and who want to keep up with a field like growth theory will find merely one important article approximately every two years among the ever growing pool of articles. 


\section{Figure 1: Citation Inflation in the Social Sciences, 1969-1996}

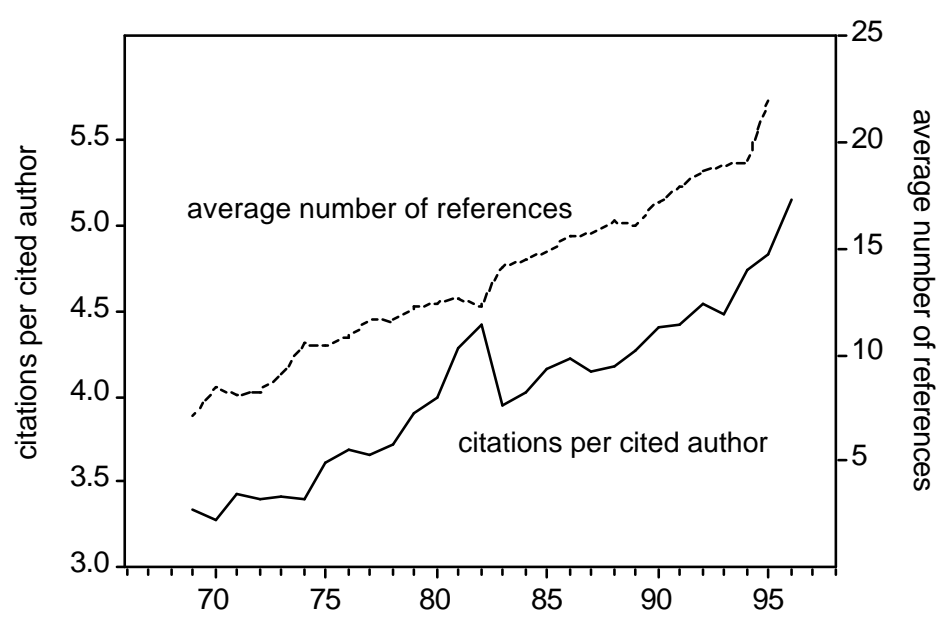

Source: ISI, Journal Citation Reports

The sheer numbers evoke the problem of attention. Each year more articles appear in the domain that we scientists are expected to cover. So the question is: which articles to read, which work to take seriously? That is one side of the problem. On the other side each of us faces the daunting prospect that each year our articles compete with ever more other articles for attention. As we know for ourselves, nobody can read all. People have to be selective and so will they select articles to pay attention to.

The poignancy of this question of attention is accentuated by the second harsh fact that concerns the skewed distribution of attention. It has long been noted that inequality in attention given to ideas is highly skewed toward 'giants' in a particular discipline. The registration of inequality in science essentially started with the work by Lotka (1926) who formulated the following law of scientific productivity: if $n_{1}$ is the number of scientists who publish one article, then the number $n_{k}$ of scientists publishing $k$ articles (for $k>1$ ) in the same field can be gauged on the basis of the following equation: $n_{k}=n_{1} / k^{2}$. Hence, if 1,000 scientists publish 1 article during their lifetime then 250 will have produced 2 articles, 111 will have written 3 articles, etc. Later, formulations of inequality distributions in scientific productivity were made by Price (1976) who formulated a variant of Lotka's Law, viz. one half of the total output of articles published by a population of $N$ scientists will be the work of $\sqrt{ } N$ most productive members of the population. Holub et al. (1991) made a variant of Price's claim by stating that the number of important publications in a science is the square root of the total number of publications in a research field. All these statistical theories of inequality distributions share the common trait that they lack a behavioural theory of citation, which stands to reason as most inventors of these distributions believed that the making of science was ruled by an iron law. Under these circumstances the main task of a scientometrician' would then amount to discovering the natural constants of the process of publication and citation. David (1994) has argued that sociologists and economists of science still have some explanatory work to do if they want to understand more clearly why the large majority of articles in social science receives so little attention and why just a small percentage of articles makes the grade in terms of a large number of citations. 
Figure 2: Cumulative distributions of impact scores of SSCI journals, 1999

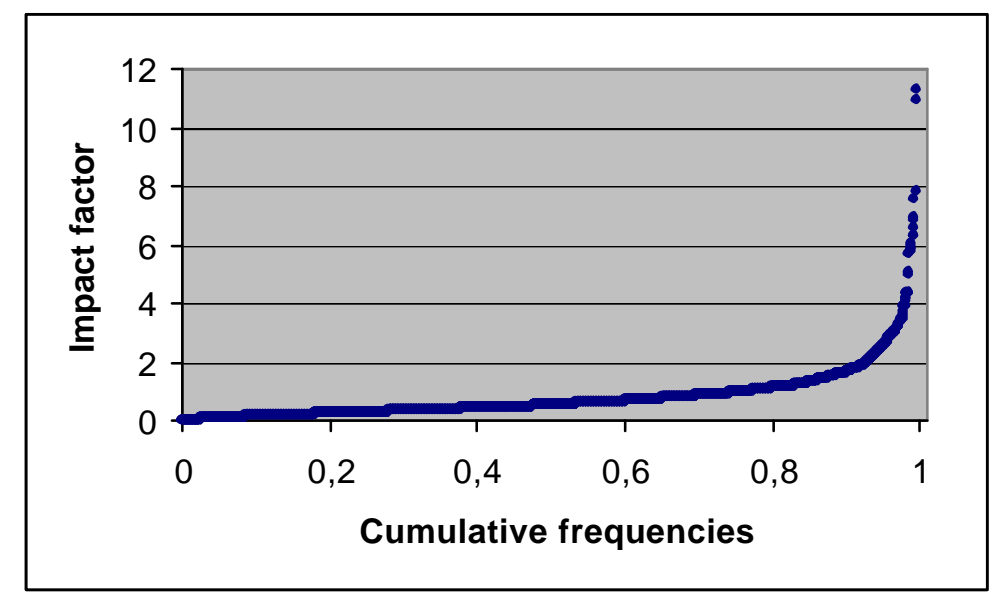

Source: ISI, Journal Citation Reports (2000)

To get an idea of how skewed the rewards are distributed just take a look at Figure 2 where the cumulative distribution of the impact factor of all journals registered by the Social Science Citation Index (1,698 journals). The super star SSCI journal has an impact factor of 11.3, which means that the average article in this journal receives 11.3 citations (including self-citations) in the first two years after the publication date. The most visible characteristic of the distribution of journals is however the almost rectangular shape. For 80 percent of all journals the influence on the scientific community is small if not negligible. If the distribution would reflect the income distribution of a country no president or minister of a civilised nation would hesitate at designing a redistribution of income. Still, scientists seem to accept their 'income distribution' as normal. The median impact factor for the social sciences journals is 0.5 (which includes self-citations of authors) whereas the top-10 percent journal has an impact of 1.65. But let us warn you right here and now: even getting published in a major journal will not suffice to gain attention with full certainty. In the end only the top 0.1 percent of the hundred of thousands articles and books published each year receive a great deal of attention (see Laband, 1986; Garfield, 1990; and Durden and Ellis,1993). The majority of the research done, published or not, passes by unnoticed. Welcome to the harsh reality of the scientific world.

\section{How to Account for the Harsh Facts: The Factor of Attention}

The big question surrounding these harsh facts is not whether this state of affairs is fair, because fairness does not play an overriding part in superstar professions. As the Leamer quotation at the very beginning of this article made clear, it is part of the academic game to get attention. The facts tell us that this is a complicated game. One question we want to ask concerns the institutions that structure this game and help producers and consumers of science cope with the excess. In the back of our mind is the question whether these institutions may transfer to world of digital communication. By focusing on the factor of attention, we downplay the role of truth as the discriminatory and allocative device. When many claims to the truth circulate, attention is the sine qua non for a claim to be shared and become part of the "stock of knowledge." 
Attention stems from the Latin attendere, and connotes the act of attending one's mind or consciousness to a phenomenon. In this cognitive characterization attention is the mental activity of selecting and focusing (see for instance Berlyne, 1960 and Kahneman 1973). The question here is how individuals cope with the excess of sense-data and how their selection mechanisms work. Although this cognitive perspective is of interest not only to marketeers but also to students of scientific processes - think for example of the cognitive impact of rhetorical devices - , it has a disadvantage that it focuses in the individual whereas we are dealing with interactions and communications among individuals.

We focus on the attention as a social phenomenon that is to be detected not inside the head of individuals but in their interactions. Attention in this sense is the density of the signals that relate to a particular argument, idea, article, research program, scientist, discipline, or science as such. No attention for an article means that nobody talks, write or communicate in any way about it. This is virtually impossible as the article will most likely appear in a table of content and in some lists of publications (of the department of the author, for instance); any such signal represents attention. No attention for an idea is easier to conceive: the person with the idea may simply abstain from any communicative action whatsoever to guarantee that no-one else is able to pay it any attention. When people talk about an article, they give it attention; when they cite it in their own articles they do not only give it attention but also increase the chance for the article to receive more attention like when other people begin talking about the the cited idea. Attention appears in numerous forms: the frequency in which a work is talked about within the scientific community or a subset thereof, the haggling over the order of names on articles, the number of citations a paper receives and positions and prizes awarded because of original work. Accordingly, in our usage 'attention' stands for the intensity with which any product of scientific imagination (an argument, a idea, an article, a scientist, a research programme, an oeuvre, a discipline) is communicated in the scientific community.

Knowledge about how attention is formed and distributed in the community of scientists is in our opinion the key to understanding the creation and diffusion of ideas in science, that is, how science works. Let us first see how far we get when we consider the stylised facts in the light of an economist's perspective.

\subsection{PLAIN INCENTIVES}

Economists ordinarily refer to the market place of ideas and apply the logic of the market to the way science works. The work by Levy (1988) and Franck (1999) falls squarely in that tradition. Levy views the strive for fame as an ordinary market activity and models fame and lifetime income as a trade-off. In order to attain fame later you have to sacrifice income and time. He shows that in the days of Jevons and Marshall fame would be cheaper to maintain than in the days of the Academic Professional like Samuelson and Friedman. Of course, the difference is easy to explain as knowledge diffusion was very slow in the 'amateur' days, books were the embodiment of the final statement on a subject contrary to the day of the professionals who use journals as means of communication. Levy's treatment is however rudimentary and hardly reflects the trade-off for the common scientist whose work has a slight chance of being noticed.

Franck (1999) corrects this biased view of science by explicitly considering attention in the context of knowledge production. He claims attention to be the main input to knowledge production and recognition, or attention income, as the factor that motivates scientists most (Franck, 2000: 1-6). Attention, or recognition of one's efforts, must compensate for the pecuniary income foregone. It does well for our self-esteem and sense of satisfaction. Accordingly the assumption is that individual 
scientists will try to maximize the attention to their own work. They have an incentive to pay attention to the work of other scientists insofar as that work will enhance their own productivity and hence the chance for getting more attention. He characterizes the world of science as a closed system of attention: the assumption here is presumably that scientists operate in more or less fixed pools of people and papers calling for and paying attention. In that regard this world differs from the world of musicians, say, as musicians have to seek attention for their work outside their own circle. Scientists most of all pay attention to each other.

The economic question concerns the efficiency of this exchange of attention. According to Franck the outcome is efficient if the intensity of the attention that papers receive corresponds with their scientific value. We thus have the classic Smithian problem: does a "free" economy of attention in which individual scientists try to maximize attention for their own work, generate optimal outcomes? Franck does not believe this to be the case. All is well according to Franck as long as scientists are citation maximizers and citations measure scientific value accurately. The attention they can muster for the work of fellow scientists is limited in its intensity and extensity. In other words, attention is scarce and because of this scarcity they have developed a variety of practices to deal with the factor attention. It is, of course, not the only motive which makes scientists tick, but it certainly is nowadays the dominant driving force. Science involves communication and communication happens because people not only ask for attention but also are willing to give it. Getting published is a sine qua non for gaining attention beyond one's friends and immediate colleagues.

Franck's analysis is designed to deal with the efficiency question. It does not account for the stylised facts of inflation in publications and citations and the skewed distribution of citations. The competitive market model is of no use for explaining these as it presupposes that the market for ideas works like a spot market: everyone receives his marginal productivity or put differently, the price paid for an idea (e.g. by citing an article) reflects its marginal usefulness. Spot markets fail however to explain why reward and productivity seem to be distributed by the Robin Hood character (once designed by the Monty Python team) who takes from the poor and gives to the rich.

\subsection{SOPHISTICATED INCENTIVES: STARDOM}

A possible starting point for putting the phenomenon of giants and dwarfs in perspective can be found in Rosen's theory of superstars (Rosen, 1981), a theory which claims that initial endowment differences, however small, tend to be magnified by the market size or the audience for a service or idea. In science this phenomenon is clearly visible as an extremely small number of researchers receives a disproportionate amount of attention. Cox et al. (1997) show how the economics publishing industry conforms remarkably well to the laws of superstardom. In order to test the theory of superstars for science two elements of science could possibly explain the extreme skewness of distribution across social scientists, viz. reputation and the size of markets. Rosen focussed on the role of market sizes in determining the rewards on labour markets for creative professions. Rosen (1981, p. 845) distinguishes two characteristics of the superstar: "first, a close connection between personal reward and the size of one' s own market; and second, a strong tendency for both market size and reward to be skewed toward the most talented people in the activity." The result of it all is that "small differences in talent become magnified in larger earnings differences, with greater magnification of the earnings-talent gradient increases sharply near the top of the scale."

The skewed distribution of returns can be explained by the convexity of the sellers' revenue functions which implies that the rewards are more skewed than the distribution of talent. Apparently superstars have something extra, the gift of the gab or perhaps they are simply better salesmen. In 
writing on the technique of persuasion George Stigler (1955) once stated that new ideas are even harder to sell than new products: "Wares must be shouted - the human mind is not a divining rod that quivers over truth." General repetition, inflated claims and disproportionate emphases are according to Stigler the strategies that accompany the adoption of every new idea in economic theory. This element of Rosen's theory may perhaps be one of its weak points as the skills to sell may in fact be a necessary part of talent. The rewards of superstardom can be captured by imperfect substitution among authors. Authors of lesser talents are often a poor substitute for the authors who think great thoughts, or to put it less bluntly from the consumer's side, reading ten mediocre articles do not make up for the read of one excellent article. A distinguishing characteristic of the superstar is therefore that there is a 'marriage' of buyers and sellers: audiences are assigned to authors and if the authors plays their cards right they acquire by means of workings of the pen a top quality audience. High quality audiences are important as those audiences can reciprocate the author's efforts by citing the work in question. Furthermore, the costs of production (e.g., writing an article) do not rise in proportion to the size of a seller's market. The only hurdle one has to take is the peer review. Managing editors, editorial board members and external referees are all involved in evaluating manuscripts and ideas.

As demonstrated by MacDonald (1988) the type of reward schedule as described by Merton (1968) and Rosen (1981) is optimal as it selects the young and promising individuals in a profession or a trade in which creativity dominates the product or service produced, a feature which fits the labour market for academics well. MacDonald's model is based on a dynamic 'information accumulation process' with multiple market levels. To translate his model to suit the circumstances of science, researchers begin in the entry-level market where they compete mostly as unknowns. They receive the attention from lower ranked researchers who also have lower opportunity costs of time and who therefore can 'afford' to read the writings of these 'nobodies'. However, some of these nobodies in the entry-level market exhibit above average talent in their writings and they also receive above average attention as their work is cited on a modest but given their standing at an exceptional rate. These exceptional researchers are then given a chance to compete in more select markets where 'consumers' of knowledge have more human capital than the average consumer in the entrymarket and whose time is more valuable than those lower ranked consumers. In each higher market level 'consumers' are willing to pay a premium to enjoy or read the lectures and writings of the higher quality scientists. Furthermore, MacDonald (p. 162) made the observation that in occupations in which performance is stochastic and in which past performance is a poor predictor of current performance, the chance of leaving such an occupation will be slight.

The evidence of the tolerance for below average work is ample in science. Siow (1991) showed that for scientists working in mathematics and economics first impressions, as displayed in the quality of their first publication, are in practice not as important as they appear in theory. And on a more general note, both editors and referees are noted to err in judging quality, where the type Ierrors of judgement (low quality work is accepted for publication) are reflected in uncitedness rates.

There are, however, two sides to the coin of success. A superstar's gain is the loss of the researcher working in the backwaters of science. The time which an academic spends on reading journal articles (or contributed articles which need refereeing) is limited and in the competition for this reading time contributions from new authors have to stand out markedly if they want to catch the attention of authors with a some reputation. The phenomenon of the skewed distribution of recognition has been aptly coined the Matthew effect in science by Merton (1968). According to the gospel of Matthew "For unto everyone that hath shall be given, and he shall have abundance: but from him that have not shall be taken away even that which he hath." Merton made the case that this 
particular effect appears principally in either cases of collaboration or in cases of independent multiple discoveries made by scientists of distinctly different rank or status.

\section{CLUSTERS AND NETWORKS}

Scarcity, incentives, the size of the "market", a customary set of economic concepts appear to help us account for the skewed distribution of citations. However, the issue of the inflation of citations still needs to be addressed and we think we need to understand better how scientists cope with the problem of attention. To those ends we now we turn to the institutions that shape and characterize the worlds of the sciences. Our claim is that the main institution that helps scientists cope with the problem of attention (i.e. the channelling and distribution of attention) is the clustering in groups and discursive entities. Scientists cluster in universities, form departments in accordance to disciplines, set up barriers to entry, organize professional associations in order to organize conferences and issue journals, constitute schools, subscribe to research programmes, develop specialized research communities which will organize specialized conferences and issue specialized journals, and form networks of like-minded souls. All these institutions help to define, bolster or protect a space of attention, that is, a concentration and intensification of signals interchanged. It helps explain why innovations in science are geographically localized and not evenly dispersed throughout the world. In order to make an intense conversation possible face-to-face communication with like-minded colleagues appears to be essential. The University of Chicago is perhaps one of the most outstanding examples in economics (Van Dalen, 1999) but the importance of place runs throughout the history of other sciences as well (Zuckerman, 1977).

There are good epistemological reasons why scientists operate this way. It is not just the excess that forces them to be selective and concentrate on a limited domain of scientific production. They also form and join communities of fellow scientists because it is the way to develop, share and sustain whatever knowledge they have. Knowledge is not a thing that is lodged in a human mind and can be communicated by means of bits of information to another mind (Maturana and Varela 1980, van de Velde, 1999). Knowledge is not a product that can be stocked and transferred. It is rather an activity that people engage in. Maturana has introduced the notion of autopoietic system (selfcreation) to express the idea that each of one us operates in a more or less autonomous system that continues to reproduce itself. "From an epistemological point of view, autopoiesis implies that agents are open to data but close to knowledge - new data is only potential knowledge." (Van de Velde, 1999: 5) When new data affect the system (i.e. get attention), the system will have to deal with them in one way of another. The important point is that people can not know what other people know; they can only process signals that others send. Most signals will bounce off (fail to get attention); others will be seriously distorted in the processing. To contain the potential chaos and to restrict the uncertainty of this process scientists form groups or communities. A group allows for and stimulates a frequent and intensive interchange of signals. The members will never fully know what the others know $^{2}$ but because of their systems may have to process so many similar signals and hence share so many codes and the like that they begin to develop similar responses to new signals. Matunara calls such a process "structural coupling" and the outcome a "consensual domain" (see Maturana and Varela, 1980). We see in a consensual domain an attention space in the sense that it concentrates the attention of all those connected with it.

Accordingly, we would expect that scientists will benefit from an association with other scientists. Support for this expectation we find in Collins' impressive study The Sociology of

\footnotetext{
${ }^{2}$ Even partners in a marriage will fail to know fully what the other knows, their (hopefully) frequent and intensive interactions notwithstanding.
} 
Philosophies, A Global Theory of Intellectual Change (1998). Collins depicts a "dynamics of conflict and alliance" in the formation of important philosophical 'schools' or 'networks' such as the German idealists (Kant cs), the Vienna Circle and the neo-Confucians. His extensive research brings out a few remarkable patters: important philosophical schools (i.e. those that survive their times and make it into the textbooks) come about within a restricted time span (30 years or less), within a restricted network-just as we would have expected. According to Collins "[t]he social structure of the intellectual world, the topic of this book, is an ongoing struggle among chains of persons charged up with emotional energy and cultural capital, to fill a small number of centers of attention." (ibid, $\mathrm{p}$. 14, italics added)

Collins conceives scientists as being involved in interaction rituals (cf Goffman, 1967). Crucial ingredients of each interaction rituals are, for instance, the physical assembly of a group of at least two people, focused attention on the same object or action, and a common mood or emotion. Intellectuals differ from most lay groups in the self-consciousness and reflexivity of their interaction rituals; they usually receive attention only from each other. Although they may think of themselves as individuals, philosophers tend to operate in groups; successful philosophers invariably have done so. Collins has found that to be the case long before the invention of print as well as in contemporary times. Personal meetings, professional meetings, lectures, debates, seminars, departments in universities all help them to focus their attention and develop a common mood, motion, or intellectual energy.

"Without face-to-face rituals, writings and ideas would never be charged up with emotional energy; they would be Durkheimian emblems of a dead religion, whose worshippers never came to the ceremonies. Texts do not merely transcend the immediate particulars of the here-and-now and push towards abstraction and generality. To be oriented toward the writings of intellectuals is to be conscious of the community itself, stretching both backward and forwards in time. (ibid, p. 27).

Thus intellectuals overcome the problem of abundance-- too many others calling attention for too many ideas. They form distinctive conversations to generate an inside world. The conversation compels insiders to focus on contributions of other insiders and to ignore all others. Collins simply observes that for any conversation to be vital and have a lasting impact, personal interactions are a necessary condition.

His investigation of "centers of attention" through time adds another interesting insight: important philosophical schools invariably are in competition with other schools, but never with more then two others. The latter finding Collins calls the law of small number. It appears that three rival schools are all that the philosophers can handle. More rival positions would scatter the attention too much and dilute the focus of the conversation to the point of fragmentation and subsequent disintegration.

Accordingly, the most enduring strategy to make the process of gaining, distributing and sharing attention manageable is to create clusters which we also might call attention spaces. Scientists specialise and form clusters in their specialisation, each with its own 'discursive practice' or 'conversation', its own journal, association. When the chance of being noticed is minimal in the field at large, the solution is to organise or partake in a smaller subfield where the chance of being noticed is much greater. Take the example of cultural economists. Even though a few prominent economists had published on the economics of the arts in well-known journals, less prominent economists failed to gain the attention of the core economics journals. So they formed their own association that issues 
a newsletter, organises biannual conferences, started up a new journal and tried to be included in the social science citation index (SSCI) and have the abstracts published in the Journal of Economic Literature. The advantage of the association, the journal and the conferences was the attention by a reasonably well-defined group for work on the economics of the arts. The attempt to get included in the SSCI and the JEL represents an attempt to gain legitimacy for the subfield and thus to secure its sustainability. Failure to do so would have a negative effect on the incentive to publish in the Journal of Cultural Economics because such a publication would not count for much in tenure and promotion decisions. The example indicates that the organisation of a space of attention is not only important for the satisfaction of those working in the field of cultural economics, but also serves the career interests of those participating.

Clustering is a condition for making the process of attention seeking and getting more manageable. As we saw before, stars emerge when there are lots of people who want to pay attention and want to share their attention. Stars, are therefore, a phenomenon of large fields, like the field of economics in general. Small clusters tolerate stars less well and will more equally distribute the attention among the "members". The downsizing of clusters, therefore, is an effective response to the skewed distribution of attention.

The clustering also accounts for the inflation of publications and citations (cf. Van Raan, 2000). Each cluster generates its own publications and forms a mutual citation society. Those who write in the Journal of Cultural Economics cite other articles in the same journal. So even if these articles are not cited elsewhere, their citations are add to the total (provided they are included in the SSCI). The argument could also be put another way: the inflation of citations indicates a rapid expansion of the number of clusters in the world of the sciences.

In short, when you as a scientist seek recognition for your ideas, you do better joining a conversation within a cluster. That means you will have to respect its rhetoric, cite its often cited texts, attend its conferences and so on. Yet, joining a cluster does not guarantee attention. Clusters can be closed-minded. When a few of the distinctive "members" of the cluster dismiss a new idea there is the chance that the scientific community will stick to the old idea as the negative experience of a few will tip locally gathered positive experience of everyone. The interaction structure can therefore be quite powerful in its consequences.

Goyal (1999) argues that locally independent individuals may be better off when novel ideas are at stake. Local independence, i.e. individuals who do not have direct neighbours in common, allows individuals to choose different actions and learn about the potential of these actions, before information about the potential of other actions reaches them. In other words, a loosely connected society appears to be more tolerant towards novelties as the amount of experimentation with new ideas is 'optimal'.

Things become a bit more complicated if the ideas or technologies exhibit network externalities, i.e. the pay-off to an idea increases with the number of people using the good. The network externality idea closely resembles the character of a conversation topic: if everyone has read a different article a conversation would be hard to maintain. However, if everyone has read the latest article by Deirdre McCloskey a lively conversation is a real option. For the generation of attention this is an important insight. In case individuals have to choose between two or more new ideas, it is assumed that individuals are indifferent with respect to the ideas per se, but are more interested in the number of people accepting a certain idea. The market place for ideas is rather a competition for networks or standards. Expectations, coordination and compatibility of standards are then of paramount importance. Various institutional arrangements try to cover these so-called market failures and most of the issues touched upon are of relevance to the journals market as, of course, any 
journal would like to be the journal which 'dictates' what the norm of discussing economics and policy will be. Presently, US-based journals dominate mainstream of economics to the chagrin of some (Colander, 1994; and Hodgson and Rothman, 1999). ${ }^{3}$

Now which network models have been in place or are pushed forward as the ideal model for science. The model of Lone Wolves, corresponding with situation (a) in Figure 3, is clearly a much depicted extreme system for those who think isolated individuals can make contributions to science. Perhaps for the extremely gifted like Mendel or Srinivasa Ramanujan this model could be made to work, but for the large majority science is made in communities and without the interaction among individuals science would break down or produce an excessive amount of duplication. A less extreme version of the lone wolves model is to focus on the number of authors publishing a paper. Certainly in the modern world of academic professionalism team work has become the rule and solo production - written by lone wolves - has become the exception.

Figure 3: Network interaction structures: (a) Lone wolves - no interaction; (b) The Science Ideal - Full interaction; (c) Technology leader sets the standard (of language, methods, issues); (d) Learning from neighbours; (e) Minimal network structure with a core.

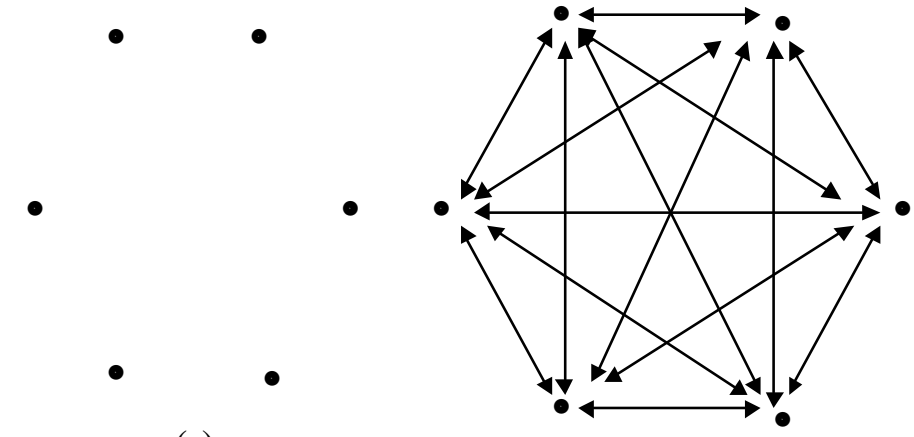

(a)

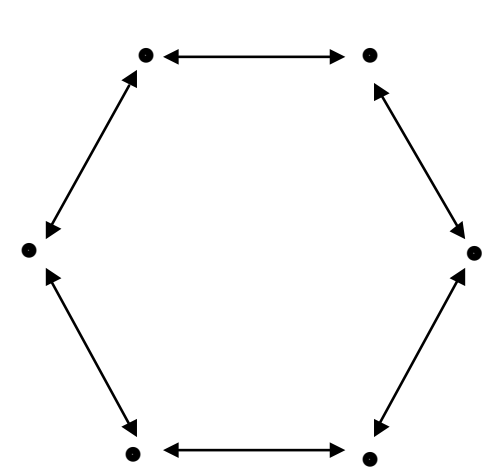

(d)

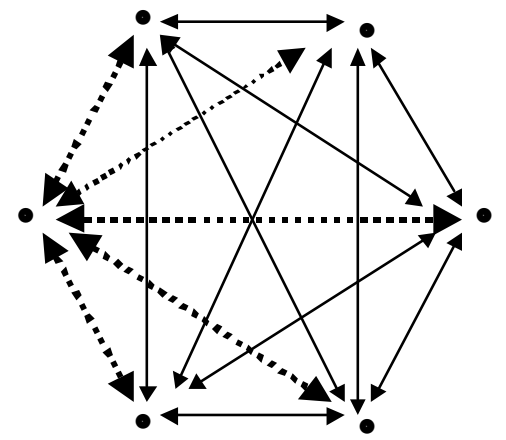

(c) (b)

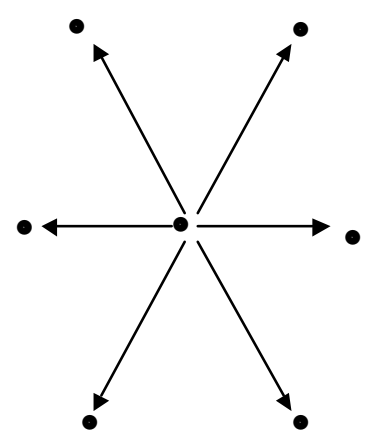

(e)

\footnotetext{
${ }^{3}$ However, Smart and Waldfogel (1996) show that manuscripts by non-top authors receive editorial treatment more favourable than their status warrants.
} 
The other extreme network structure, that of the fully integrated scientific community, corresponding with Figure (b) is also not much help in understanding science as it lacks plausibility. In a way it corresponds to the views of science as a neoclassical market of supply and demand as depicted by Franck (1999): the world of science is fully integrated and everyone has an equal chance of meeting each and every participant. And in a way it also reflects Polanyi's (1962) description of the Republic of Science a system in which science is not a solitary affair, but an activity done in 'overlapping neighbourhoods'. In solving a gigantic jigsaw puzzle science is at its best when each and every participant solves the puzzle simultaneously but in close contact with the rest of the community. That is the ideal picture of science. But one of the harsh facts is that science has to deal with an information overload. And in order to make the scientific communication possible the scarcity of attention needs to be allocated and other, more plausible network structures have arisen. Model (c) in which a leader sets the standard adds some plausibility to modelling the world of scientific publication. Indeed Frey and Eichenberger (1997) note how the US universities and journals set standards for the rest of the economic community.

And as made clear by the literature on open source projects (Lerner and Tirole, 1999) like Linux and Sendmail appearances may deceive. Most of the programming work seems to be done in an anarchistic way, but in actual fact the spontaneity is of an organised manner, often led by a charismatic leader, who divides up the work in smaller and well-defined tasks, attracts other programmers and last but not least "who keeps the project together".

Still, the star model (e), which presents the most efficient network, and the learning-fromneighbours model (d) are both closer to home. The star model comes close to how each discipline operates, with a set of core journals to which minor, more specialised journals are connected (see Stigler, 1994; Stigler et al. 1995; Van Dalen and Henkens, 1999, 2001). Notice however how the communication in this model generally moves in one direction. The intellectual triad between journals is generally one in which core journals export knowledge to specialized journals and not the other way around. The model in which we learn from the local neighbours on campus or from neighbouring disciplines also has a touch of reality as the research by Garfield (1998) on modelling the entire world of science shows.

\section{The Future of Scientific Publishing}

No matter how truthful scientific claims may be, they need to be read, talked about, and cited in order to exist. Such activity represents attention. As the ranks of scientists are swelling, the number of articles seeking attention is exploding. With so many scientists around willing and needing to give attention, the possibility of very intensive attention increases - the fortune of stardom. At the same time the chance of being crowded out in the attention game is getting bigger. In order to deal with the excess, the phenomenon of stars as well as the lack of attention for most, scientists will converge in what we have called clusters, consensual domains and centers of attention. These clusters will be part of larger fields but will be sufficiently distinctive to constitute a recognisable space of attention.

In order to guard the quality of the attention members of cluster will screen contributions. They will expect contributors to have a relevant academic degree (non-Ph.D.'s do not need to apply), an academic affiliation, and will referee the submitted texts. The evaluation will involve an assessment of rhetorical fit, that is, the overlap with the conversation that constitute the cluster.

The digitilisation of scientific publication will change scientific practice to some extent. It allows for a more direct and interactive refereeing process and it will make rankings based on citations, hits, and downloaded papers easier. Furthermore, the tracking of linkages between papers 
will make communication more intense, the linkage of databases to papers will enable more experimentation and replication can in principle yield more reliable information and the appearance of intelligent software agents who search the net in a systematic and intelligent manner will make that all relevant knowledge will be used in the production of new knowledge.

At least, in theory. In practice, one is still tempted to make use of old selection mechanisms and institutions. The Internet will in that respect not alter the fundamental principles of science as the internet itself is based on the same principles on which science is based: openness, communality and universality. The main character of science which will change is the intensity and speed of interactions, thereby reinforcing the winner-take-all character of science but also making journals truly a reflection of conversations.

Still not all is fine in the New Republic of Science as much of the future of publishing depends on how the character of Internet will develop. If it becomes a pure commercial affair in which access and distribution is restricted by private interests the character of science and therefore of journals will be debased. Intrinsic motivation is crucial when tacit knowledge must be transferred and the possible translation of indicators of 'success' (number of downloads, prints, time spent reading) in science into extrinsic and explicit incentives will disrupt the functioning of science. The distinction between the cultures of Science - norm-driven - and Technology - market-driven (Dasgupta and David, 1994) will disappear, thereby making public disclosure of results more and more susceptible to market valuation. Of course, without the Internet this process was already under way as journals and citations were already being used as discriminating factors in decision making, but the extent to which it is used will differ.

Furthermore with the increase of specialised clusters in science we will also see the appearance of more knowledge-broking journals (like the Journal of Economic Perpectives and the new journal Economic Intuition). Of course, to fill this journal type authors will have to develop more knowledge broking qualities or in case authors lack this marketing quality the brokerage function can be performed by true knowledge brokers.

Another predication about the future of publishing is that peer evaluation will become a mix between ex ante and ex post evaluation. Being an ex post evaluator will become a separate and valued quality within academia just like in open source projects, such as Linux and Sendmail (Lerner and Tirole, 1999). The Internet offers the technology to exploit alternative peer review systems. Possible suggestions for electronic publishing (see Varian, 1997), editors initially grade papers by relevance, if authors find the grade too low, they can withdraw their paper, otherwise it is put on the web and correctness and real relevance are tested ex post. Other ex post strategies which can help to the evaluation of science a spontaneous order in the new economy: (1) put all working papers on the net; (2) depending on how much times the paper was downloaded from outside the university/institute/country it can go on to the next stage, the electronic journal stage, where paper is 'printed' with (editorially refereed) reviews of readers (just like on Amazon.com), possibly with comments of the authors; (3) depending on number of citations in the SSCI/SCI the paper optionally adjusted to take account of the comments - is printed in a yearly volume of 'citation classics'.

Summing up, the coming age of electronic journals can in principle circumvent much of the inefficiencies of hard-copy journals but new distortions lurk. The basic principles of scientific communication coincide to a large degree with the principles of the internet and open source code projects. The future of electronic journals depends to a large degree on which norms and values will prevail on the net: those of the market or those of science. 


\section{References}

Berlyne, D.E. (1960) Conflict, Arousal and Curiosity, New York: McGraw-Hill.

Colander, D. (1994) 'Vision, Judgement, and Disagreement Among Economists', Journal of Economic Methodology 1: 43-56.

Cox, R.A.K., Mitchell, J.B. and Chung, K.H. (1997) 'Superstardom in the Finance, Accounting and Economics Scholarly Publication Industry', mimeo, Central Michigan University.

Dasgupta, P., and David, P.A. (1994) 'Toward a New Economics of Science', Research Policy, 23: 487-521.

David, P.A. (1994) 'Positive Feedbacks and Research Productivity in Science: Reopening Another Black Box', in: O. Granstrand (ed.), Economics of Technology, Amsterdam: Elsevier.

Collins, R. (1998) The Sociology of Philosophies, A Global Theory of Intellectual Change, Cambridge MA: Harvard University Press.

Durden, G.C., and Ellis, L.V. (1993) 'A Method for Identifying the Most Influential Articles in an Academic Discipline', Atlantic Economic Journal, 21, 1-10.

Franck, G. (1999) 'Scientific Communication - A Vanity Fair?' Science, 286: 53-55. (2000). 'In Search of Attention'. Unpublished paper, Vienna.

Frey, B.S., and Eichenberger, R. (1997) 'Economists: First Semester, High Flyers and UFOs', in P.A.G. van Bergeijk et al. (eds.), Economic Science and Practice, Cheltenham: Edward Elgar, pp.15-48.

Garfield, E. (1990) 'The Most Cited Papers of All Time, SCI 1945-1988', Current Contents, 7: 3-14.

(1998) 'Mapping the World of Science' paper at the 150 anniversary meeting of the AAAS, Philadelphia.

Goffman, E. (1967) Interaction Ritual - Essays on Face-to-Face Behaviour. Garden City, New York: Doubleday\&Company, Inc.

Goyal, S. (1999), Networks, Learning and Equilibrium, inaugural lecture, Erasmus University, Rotterdam.

Hargens, L.L., and Schuman, H. (1990) 'Citation Counts and Social Comparisons: Scientists' Use and Evaluation of Citation Index Data', Social Science Research 19: 205-221.

Hodgson, G.M., and Rothman, H. (1999) 'The Editors and Authors of Economics Journals: A Case of Institutional Oligopoly?', Economic Journal, 109: F165-F186.

Holub, H.W., Tappeiner, G. and Eberharter, V. (1991) 'The Iron Law of Important Articles', Southern Economic Journal 58: 317-328.

Kahneman, D. (1973) Attention and Effort, New Jersey: Prentice-Hall

Laband, D.N. (1986) 'Article Popularity', Economic Inquiry, 24: 173-180.

Leamer, E. (1981) 'The Hit Parade of Economic Articles', Comparative Economic Systems, 14: 3-54.

Lerner, J., and Tirole, J. (2000) 'The Simple Economics of Open Source', NBER Working Paper, no. 7600 , Cambridge, MA.

Levy, D.M. (1988) 'The Market for Fame and Fortune', History of Political Economy, 615-625.

Lotka, A.J. (1926) 'The Frequency Distribution of Scientific Productivity', Journal of the Washington Academy of Sciences 16: 317-323.

Maturana, H. R., and Varela, F. J. (1980). Autopoiesis and Cognition: The Realization of the Living. Dordrecht: Reidel Publishing Company. 
MacDonald, G.M. (1988) 'The Economics of Rising Stars', American Economic Review, 78: 155-167.

Merton, R.K. (1968) 'The Matthew Effect in Science', Science 159: 56-63.

Polanyi, M. (1962) 'The Republic of Science: Its Political and Economic Theory' in: M. Polanyi (1969), Knowing and Being, Chicago: University of Chicago Press, pp. 49-72.

Price, D.J. de Solla (1976) 'A General Theory of Bibliometric and Other Cumulative Advantage Processes', Journal of the American Society for Information Science 27: 292-306.

Rosen, S. (1981) 'The Economics of Superstars', American Economic Review, 71: 845-858.

Siow, A. (1991), 'Are First Impressions Important in Academia?', Journal of Human Resources, 26: $855-866$.

(1998) 'Tenure and Other Unusual Personnel Practices in Academia', Journal of Law, Economics and Organization, 14: 152-173

Smart, S., and Waldfogel, J. (1996) 'A Citation-Based Test for Discrimination at Economics and Finance Journals', NBER Working Paper, no. 5460. Cambridge MA.

Stigler, G.J. (1955), 'The Nature and Role of Originality in Scientific Progress', in: G.J. Stigler, 1965, Essays in the History of Economics, University of Chicago Press, Chicago.

Stigler, G.J., Stigler, S.M. and Friedland, C. (1995) 'The Journals of Economics', Journal of Political Economy, 103: 331-359.

Stigler, S.M. (1994) 'Citation Patterns in the Journals of Statistics and Probality', Statistical Science, 9: 94-108.

Tenopir, C. and King, D.W. (1998) 'Designing Electronic Journals with 30 years of Lessons from Print', Journal of Electronic Publishing, 4, http://www.press.umich.edu/jep/04-02/king.html

Van Dalen, H.P. (1999) 'The Golden Age of Nobel Economists', The American Economist, 43: 19-35.

Van Dalen, H.P. and Henkens, K. (1999) 'How Influential are Demography Journals?', Population and Development Review, 25: 229-251. (2001) 'What Makes a Scientific Article Influential?, Scientometrics, 50, forthcoming.

Van de Velde, R.A. (1999) 'Markets for Knowledge: Where minds do meet?' Unpublished paper, University of Delft.

Van Raan, A.F.J. (2000), 'On Growth, Ageing, and Fractal Differentiation of Science', Scientometrics, 47: 347-362.

Varian, H.R. (1997) 'The Future of Electronic Journals', Journal of Electronic Publishing, 4.

Zuckerman, H. (1977) The Scientific Elite - Nobel Laureates in the United States. New York: Free Press. 